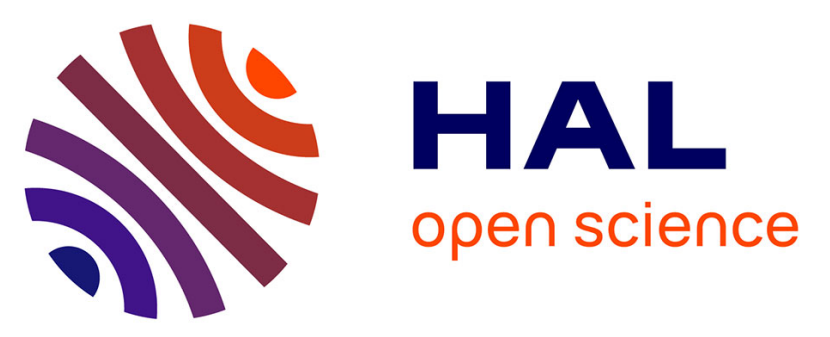

\title{
Extraction of acetylated glucuronoxylans and glucomannans from Okoume (Aucoumea klaineana Pierre) sapwood and heartwood by steam explosion
}

Errol Mougnala Moukagni, Isabelle Ziegler-Devin, Rodrigue Safou-Tchima, Nicolas Brosse

\section{To cite this version:}

Errol Mougnala Moukagni, Isabelle Ziegler-Devin, Rodrigue Safou-Tchima, Nicolas Brosse. Extraction of acetylated glucuronoxylans and glucomannans from Okoume (Aucoumea klaineana Pierre) sapwood and heartwood by steam explosion. Industrial Crops and Products, 2021, 166, pp.113466. 10.1016/J.indcrop.2021.113466 . hal-03189675

\section{HAL Id: hal-03189675 \\ https://hal.univ-lorraine.fr/hal-03189675}

Submitted on 4 Apr 2021

HAL is a multi-disciplinary open access archive for the deposit and dissemination of scientific research documents, whether they are published or not. The documents may come from teaching and research institutions in France or abroad, or from public or private research centers.
L'archive ouverte pluridisciplinaire HAL, est destinée au dépôt et à la diffusion de documents scientifiques de niveau recherche, publiés ou non, émanant des établissements d'enseignement et de recherche français ou étrangers, des laboratoires publics ou privés.

\section{(ㅇ)(1) $\$$}

Distributed under a Creative Commons Attribution - NonCommercial - NoDerivatives 44.0 
Extraction of acetylated glucuronoxylans and glucomannans from Okoume (Aucoumea klaineana Pierre) sapwood and heartwood by steam explosion

4

Errol Mougnala Moukagni ${ }^{\varnothing}$, Isabelle Ziegler-Devin ${ }^{\varnothing}$, Rodrigue Safou-Tchima", Nicolas Brosse $^{\emptyset_{*}}$

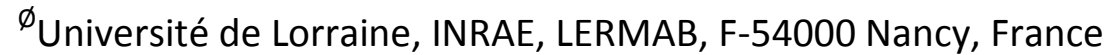

"Laboratoire de Recherche et de Valorisation du Matériau Bois (LaReVa Bois). Ecole Normale Supérieure d'Enseignement Technique (ENSET). BP 3989, Libreville, Gabon.

10

$11 *$ *orresponding author: Nicolas Brosse

12 Email address: Nicolas.Brosse@univ-lorraine.fr

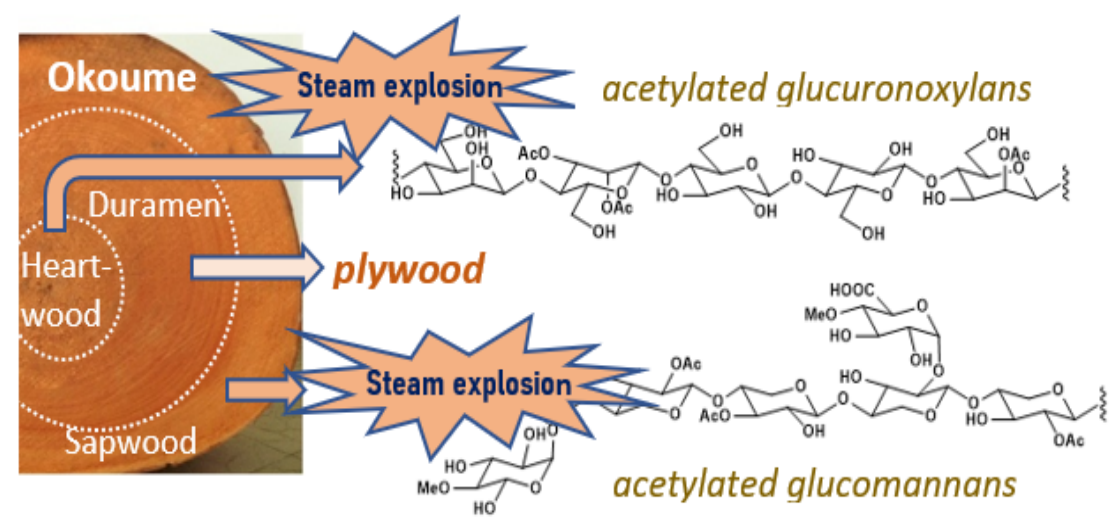




\section{Abstract}

17 Aucoumea klaineana Pierre (okoume) is a tropical hardwood of industrial importance, used for veneers and plywood production. Various conditions of Steam Explosion (SE) treatment

19 (temperature, residence time, $\mathrm{pH}$ ) have been applied on okoume co-products, sapwood

20 (SW) and heatwood (HW) for the extraction of polymeric hemicelluloses. Conventional

21 extractions with alkali or dimethyl sulfoxide (DMSO) were also performed from delignified

22 SW and HW for comparison. The hemicelluloses extracts have been characterized by HSQC-

23 NMR, FTIR, size exclusion chromatography. The acetyl contents have been determined by

24 HPLC after saponification and from HSQC spectra. Using basic impregnation prior to SE

25 ( $\mathrm{NaOH}-\mathrm{SE}$ ), high molecular mass glucuronoxylans (GX, Mw $=65-100 \mathrm{KDa}$ ) were recovered in

26 3-6\% yields. A neutral impregnation $\left(\mathrm{H}_{2} \mathrm{O}-\mathrm{SE}\right)$ produced $\mathrm{O} 2$ and/or $\mathrm{O} 3$ acetylated $\mathrm{GX}$ and

27 glucomannans (GM), preserving the acetyl moieties in a greater extent compared to the mild

28 DMSO extraction (\% Ac $\approx 6.6-8.4 \%$ and $1.0-4.1 \% \mathrm{w} / \mathrm{w}$ respectively). This study provides

29 insights on the composition of SW and HW okoume with a view to further innovative

30 processing and valorization including the preparation of films with advanced properties for

31 food packaging.

32 Key words: Aucoumea klaineana Pierre; steam explosion; acetylated glucomanans;

33 acetylated glucuronoxylans; sapwood; heartwood 


\section{Introduction}

The economic viability of the biorefineries depends of the optimal valorization of plant resources including the utilization of non-cellulosic constituents. Hemicelluloses are among the main components of wood and constitute a vast, heterogeneous and complex family of polysaccharides, containing diverse sugars and uronic acids (Ishii et al., 2001, Chadni et al., 2019). Hardwood hemicellulosic fraction is mainly composed of glucuronoxylans $(\approx 15-30 \%$ of wood) which have a backbone of $\beta$ - 1,4-linked xylose residues substituted with $\alpha$-linked 4$O$-Me- $\beta-D$-glucopyranosyl uronic acid on $0-2$ of xylosyl residue. Hardwood can also contain a minor amount of glucomannans ( $\approx 4 \%$ of wood) which have a backbone of $\beta$ - 1,4 -linked glucopyranosyl / mannopyranosyl units in a linear or slightly branched chain. These polysaccharides are usually diversely acetylated on the sugar backbone (Willfor et al. 2005). Unlike cellulose, which has been used industrially for a very long time, applications involving polymeric hemicelluloses are rare and the potential of hemicelluloses is still very little exploited. However, due to their chemical structure and high molar masses, hemicelluloses can be used to produce promising materials for various applications. One of the most studied applications for polymeric hemicelluloses is the design of films with advanced properties (e.g. biodegradability, edibility, barrier effect) for food packaging (Chadni et al., 2020, Zhao et al., 2020).

Various processes have been proposed for the recovery of hemicellulosic polymers from lignocellulosic matrix including alkali extraction of xylans and/or glucuronoxylans from agricultural co-products and liquid hot water extraction (Zhao et al. 2020). It has also been reported that galactoglucomannans can be recovered from the water stream of thermomechanical pulping of softwood using membrane technologies (Kishani et al., 2018, Willfor et al, 2003). The recovery of acetylated hemicelluloses could be of great interest for biological and material applications since acetylation degree affects the accessibility of polysaccharides to microbes, their solubility in water (Michalak et al. 2018, Voepel et al. 2009) and the physico-chemical properties of hemicelluloses-based materials (e.g. barrier properties of films, Kishani et al., 2018). However, the recovery of acetylated and high molecular mass hemicelluloses from wood with a minimum of degradation is still challenging. In fact, the currently applied methods usually rely on partly modified and deacetylated polysaccharides. For characterization 
purpose slightly modified and acetylated hemicelluloses can be recovered from holocellulose by DMSO extraction (Evtuguin et al. 2003, Marques et al. 2010). Steam explosion (SE) is one of the most promising processes for biomass fractionation and pretreatment. SE is a thermo-mechanico-chemical treatment involving a steaming step followed by an explosive decompression provoking a partial breakdown of the lignocellulosic complex (Espirito Santo et al., 2020, Marqes el al., 2020, Inseemeesak and Areeprasert, 2020). This process is commonly used for increasing the accessibility of cellulose to enzymatic hydrolysis and has been developed, even at commercial stage, for cellulosic bioethanol production. More marginally, SE has also been described for high molecular mass hemicelluloses extraction from lignocellulosic biomass. Compared to a hot water extraction, it has been demonstrated by Wojtasz-Mucha et al. (2017) that SE provoked a more effective hemicelluloses extraction due to the advective mass transport during the pressure release step (explosion). Krawczyk et al. (2008) reported the isolation of arabinoxylans from barley husks by SE after water impregnation and ultra-filtration. In our group, we studied the extraction of arabinoxylans and galactoglucomannans from spruce by SE (Chadni et al., 2019, 2020). Extraction selectivity as a function of the $\mathrm{pH}$ of the SE treatment was demonstrated: for a basic impregnation arabinoglucuronoglynans were recovered in relatively high yields whereas for water impregnation highly acetylated galactoglucomannans were isolated. It was concluded that SE could constitute an effective technique for the recovery of slightly modified and acetylated hemicelluloses from wood of application interest (e.g. food packaging).

Aucoumea klaineana Pierre (okoume) is a fast-growing hardwood species of great industrial importance in Central-Africa. Okoume is primarily used for veneers and plywood production. In Gabon, the okoume wood industry produces approximatively $1.510^{6} \mathrm{~m}^{3}$ of transformed wood and $750000 \mathrm{~m}^{3}$ of waste per year currently not properly used. In wood stem, heartwood (HW) is the inner part characterized by its high mechanical properties and sapwood (SP) the outer part with a higher porosity and moisture content. Due to these properties, okoume SW and HW have been considered as low value coproducts, excluded from industrial transformation such as trenching, veneers and plywood production (Ngwa Obame et al., 2019). There are relatively few publications concerning the comparison between sapwood (SW)/heartwood (HW) composition. Unlike HW, SW is comprised of living cells and allows the water transport and nutrients storage, characterized by a higher 
porosity and permeability. Willford at al. reported in 2005 the amount and composition of sugars in SW and HW of 11 industrially important hardwood species from temperate areas (Willfor et al. 2005). More recently, extractives content of bark, SW and HW of okoume were described (Engozogho et al., 2015) but to the best of our knowledge, the sugars composition of SW /HW of tropical species has never been investigated. However, in a context of an optimal valorization of bioresources, a better knowledge of the chemical composition of the different parts of industrial wood, including co-products, is needed.

In previous papers, we have described organosolv and SE pretreatment of okoume SW under various conditions for lignin extraction and characterization but also for ethanol production (Ngwa Obame et al., 2019, Safou-Tchiama et al. 2016). The goal and the novelty of the present work are twofold: (1) to analyze the hemicelluloses composition of HW and SW of a tropical hardwood species and (2) to study the recovery of polymeric hemicelluloses from hardwood during SE pretreatment for further utilizations. A detailed characterization of acetylated hemicelluloses was carried out by NMR and chromatographic methods in order to better understand the parameters impacting the structure of the extracted polysaccharides, to anticipate their future applications and facilitating further processing.

\section{Material and methods}

\subsection{Raw material}

The samples used in this study were collected from an Okoume (Aucoumea klaineana Pierre) log in the Nzamaligué natural forest of Gabon by the "Société Equatoriale d'Exploitation Forestière SEEF". The Okoume SW comes from slab waste, while the internal HW from the peeling core co-products.

\subsection{Conventional hemicelluloses extraction with $\mathrm{NaOH}$ and DMSO}

Sawdust from Okoume HW and SW $(<0.16 \mathrm{~mm})$ was Soxhlet extracted using toluene / ethanol / methanol (4:1:1 v/v/v) (Safou-Tchiama et al. 2017). The extracted sawdust was dried at $105^{\circ} \mathrm{C}$ and stored in a plastic bag at room temperature before use. Extract-free sawdust was depectinized with a $1 \%(\mathrm{w} / \mathrm{w})$ of ammonium oxalate solution $\left(2 \mathrm{~h}\right.$ at $\left.80^{\circ} \mathrm{C}\right)$ and then dried at $40^{\circ} \mathrm{C}$. Delignification was carried out in a water bath under reflux at $70^{\circ} \mathrm{C}$ by dispersing $1.5 \mathrm{~g}$ of depectinized sawdust in $125 \mathrm{~mL}$ of deionized water. Subsequently, $1 \mathrm{~g}$ of sodium chlorite and $1 \mathrm{~mL}$ of glacial acetic acid were added every $2 \mathrm{~h}$ until complete bleaching of the biomass. The delignified residue was carefully washed with deionized water 
130 and filtered under vacuum. The white fibrous solid residue (holocellulose) was collected and 131 dried at $40^{\circ} \mathrm{C}$. Alkaline extraction was carried out under magnetic stirring at $70^{\circ} \mathrm{C}$ with $1 \mathrm{~g}$ of 132 dry holocellulose in $50 \mathrm{~mL}$ of $2 \%(\mathrm{w} / \mathrm{w})$ of $\mathrm{NaOH}$. After $2 \mathrm{hrs}$, the liquid phase was recovered. 133 The residue was extracted again with $50 \mathrm{~mL}$ of $2 \% \mathrm{NaOH}$ for $2 \mathrm{hrs}$. Both liquid phases were 134 acidified with $20 \%(\mathrm{w} / \mathrm{w})$ of acetic acid to a pH between 5.5 and 6 . The hemicelluloses 135 precipitated by the addition of 3 volumes of ethanol were recovered by centrifugation at $4000 \mathrm{rpm}$ for $10 \mathrm{~min}$ at room temperature. The recovered hemicelluloses were dried at $40^{\circ} \mathrm{C}$ and stored in plastic jars before analysis. The hemicelluloses yields were calculated as mass percentage of dry wood. The DMSO extraction of hemicelluloses was performed on holocellulose (1:25 solid/liquid) under magnetic stirring for $15 \mathrm{hrs}$ at $70^{\circ} \mathrm{C}$. Three volumes of ethanol were added. The hemicelluloses were recovered by centrifugation at $4000 \mathrm{rpm}$ for $10 \mathrm{~min}$ and drying at $40^{\circ} \mathrm{C}$. Yields of hemicelluloses were calculated as mass percentage of dry wood.

\subsection{Extraction of hemicelluloses by steam explosion}

144 Extraction of hemicelluloses by SE has been carried out by adapting the protocol described

145 by Chadni et al. 2019 Sawdust from Okoume HW and SW of about $2 \mathrm{~mm}$ size was first dried 146 at $105^{\circ} \mathrm{C}$ overnight. Then $50 \mathrm{~g}$ of biomass were impregnated for $15 \mathrm{hrs}$ in $1 \mathrm{M}$ aqueous

$147 \mathrm{NaOH}$ (solid/liquid ratio 1:7, $\mathrm{NaOH}-\mathrm{SE}$ ) or in water (solid/liquid ratio 1:7, $\mathrm{H}_{2} \mathrm{O}-\mathrm{SE}$ ) before SE 148 (Fig. 1).

149 The impregnated sawdust was then filtered and placed directly into a $2 \mathrm{~L}$ SE reactor. The 150 sawdust was treated by injection of saturated steam at various temperatures and residence 151 times (see Table 1), then a pneumatic ball valve was opened to abruptly drop the pressure 152 and transport the biomass to the explosion chamber. The steam explosions were set at 153 temperatures between $170^{\circ} \mathrm{C}$ and $210^{\circ} \mathrm{C}$ and a residence time of $5 \mathrm{~min}$ to $10 \mathrm{~min}$. The 154 severity factor for each experiment was calculated by correlating temperature and retention 155 time using the following equation (Overend and Chornet, 1987):

Eq. 1 156

$$
S=\log \left[\mathrm{t}_{\mathrm{s}} \cdot \exp \left(\frac{\mathrm{T}-100}{14.75}\right)\right]
$$

$\mathrm{t}_{\mathrm{s}}$ is the residence time $(\mathrm{min})$ and $\mathrm{T}$ is the temperature $\left({ }^{\circ} \mathrm{C}\right)$.

157 After SE pre-treatment, the hemicelluloses-rich liquid fraction was separated from the 158 treated wood by filtration. For $\mathrm{NaOH}-\mathrm{SE}$, the $\mathrm{pH}$ was adjusted between 5.5 and 6 with $\mathrm{H}_{2} \mathrm{SO}_{4}$

$15972 \%(w / v)$. The liquid fraction was concentrated using a rotary evaporator until a volume of 
$160 \approx 100 \mathrm{~mL}$. The hemicelluloses were precipitated with 4 volumes of ethanol, then separated

161 by centrifugation at $40,000 \mathrm{rpm}$ for $10 \mathrm{~min}$. The supernatant was gently removed and the

162 solid (composed of polymeric hemicelluloses) was retained for the dialysis step. The dialysis

163 was performed for 3 days by filling a dialysis tube (cut-off of $2.5 \mathrm{kDa}$ ) with the hemicelluloses

164 solubilized in ultrapure water. Finally, the dialysate consisting of hemicelluloses was freeze-

165 dried.

$166 \quad$ Fig.1

\subsection{Measurement of monosaccharides and uronic acids by HPEAC-PAD}

The processing and analysis of the chemical composition of the extracts was performed using the National Renewable Energy Laboratory (NREL/TP-510-42618) standard. Monosaccharide and uronic acid concentrations were quantified by high performance anion exchange chromatography coupled with a pulsed amperometric detector (HPEAC-PAD: Dionex ICS-3000). The separation was carried out on a CarboPac PA20 (Dionex) column at a temperature of $35^{\circ} \mathrm{C}$ and with an isocratic eluent flow rate of $0.4 \mathrm{~mL} \cdot \mathrm{min}^{-1}$, with the

174 following composition: $99.2 \%$ ultrapure water / $0.8 \%$ of $250 \mathrm{mM} \mathrm{NaOH}$ (0-20 min) ; 75\%

175 ultrapure water / 20\% of $250 \mathrm{mM} \mathrm{NaOH} / 5 \% 1 \mathrm{M}$ of $\mathrm{CH}_{3} \mathrm{COONa}-20 \mathrm{mM} \mathrm{NaOH}$ (20-37 min)

176 and $40 \%$ of ultrapure water / $20 \% 250 \mathrm{mM}$ of $\mathrm{NaOH} / 40 \%$ of $1 \mathrm{M} \mathrm{CH}_{3} \mathrm{COONa}-20 \mathrm{mM}$ of

$177 \mathrm{NaOH}(37-45 \mathrm{~min})$ The separation was performed within 45 minutes. Calibration was

178 performed with seven calibration points. This method allowed the simultaneous

179 identification of the following sugars: galactose (Gal), glucose (Glc), mannose (Man),

180 rhamnose (Rha), xylose (Xyl), arabinose (Ara), and glucuronic acid GlcA and galacturonic acid 181 (GalA).

\subsection{Determination of acetic acid by high performance liquid chromatography (HPLC)}

183 The acetic acid content of hemicelluloses was determined by adapting the protocol of Yuan

184 et al (2006). $1000 \mu \mathrm{L}$ of the oligosaccharide solution (10 mg in $5 \mathrm{~mL}$ of water)) were

185 saponified with $\mathrm{NaOH}(1250 \mu \mathrm{L}$ at $0.4 \mathrm{M})$ for 2 hours in the dark, at room temperature, in a 5 $186 \mathrm{~mL}$ volumetric flask. The reaction was stopped by addition of $\mathrm{H}_{3} \mathrm{PO}_{4}$ at $0.4 \mathrm{M}$. This solution 187 was analyzed by high performance liquid chromatography coupled with a UV detector

188 (Shimadzu Prominence) using a Rezex ${ }^{\mathrm{TM}}$ RHM-Monosaccharide $\mathrm{H}^{+}(8 \%)$ column with sulfuric 189 acid $\left(\mathrm{H}_{2} \mathrm{SO}_{4}-5.10^{-3} \mathrm{M}\right)$ as the mobile phase with an isocratic flow rate of $0.8 \mathrm{~mL} \cdot \mathrm{min}^{-1}$ and a 190 temperature of $60^{\circ} \mathrm{C}$; the wavelength for detecting acetic acid was $210 \mathrm{~nm}$. An external 191 calibration with 6 calibration points was performed. 
193 Prior to the analysis, $5 \mathrm{mg}$ of hemicelluloses were dissolved in $2.25 \mathrm{~mL}$ of $0.25 \mathrm{M} \mathrm{NaNO}_{3}$.

194 Molecular weight distributions of hemicelluloses extracts were determined by size exclusion

195 chromatography coupled with a refractive index detector (Shimadzu Prominence). Two

196 columns coupled in series were used (Phenomenex GFC-P2000, 3000) to separate

197 hemicelluloses. The elution temperature was $35^{\circ} \mathrm{C}$ and the eluent consisted of $0.25 \mathrm{M}$

$198 \mathrm{NaNO}_{3}$ with a flow rate of $0.7 \mathrm{~mL}$. $\mathrm{min}^{-1}$. Pullulan standards of known molar masses were 199 used for calibration.

\subsection{Fourier transform infrared spectroscopy}

The hemicelluloses obtained were subjected to Fourier Transform Infrared Spectroscopy (FTIR) analysis. The infrared spectra were performed using a Thermo Scientific Nicolet 7600 IR-FT spectrometer over a frequency range between $4000 \mathrm{~cm}^{-1}$ and $650 \mathrm{~cm}^{-1}$.

2.8. HSQC 2D NMR and calculation of the Degree of Acetylation $\left(D S_{A c}\right)$

The 2-dimensional nuclear magnetic resonance (NMR) analyses of heteronuclear singular quantum coherence (HSQC) were performed on a $400 \mathrm{MHz}$ Bruker instrument with a standard Bruker program. The hemicelluloses from the steam explosion and those extracted by $\mathrm{NaOH}$ from the bleached wood were dissolved in $99.7 \%$ deuterium oxide $\left(D_{2} O\right)$, while the hemicelluloses extracted by DMSO from the bleached wood were dissolved in $99.9 \%$ dimethyl sulfoxide d6 (DMSO-d6). The number of collected complex points was 1024 for the $1 \mathrm{H}$-dimension with a relaxation of 1.5 - and 256-time increments were recorded in 13C-

212 dimension. HSQC spectra were taken at room temperature.

Eq 2. $D S(\mathrm{Ac}) X y l p=\frac{\frac{[\mathrm{Ac}]^{\mathrm{a}}}{[\mathrm{Man}+\mathrm{Xyl}]^{\mathrm{b}}}}{1+\frac{[\mathrm{Man} \mathrm{Ac}]^{\mathrm{c}}}{[\mathrm{Xyl} \mathrm{AC}]^{\mathrm{c}}}}$

Eq 3. $\quad \operatorname{anp}=\frac{[A c]^{a}}{[M a n+X y l]^{b}}-D S A c$ Xlyp 


\section{Results and discussion}

\subsection{Composition}

The compositions of okoume sapwood (SW) and heartwood (HW) used in this study and given in the Table 2 are in accordance with previous studies reported by Safou -Tchiama et al. (2007). In the present study, a comparable amount of Klason lignin and glucose and a substantially lower proportion of xylose and mannose was found.

\section{Table 2}

The polymeric hemicelluloses were recovered after SE of okoume SW and HW from the liquid stream of the process by ethanolic precipitation and dialysis. Two different impregnation conditions of wood sawdust prior to SE were examined (neutral and alkali impregnation) and three different experimental conditions $\left(170^{\circ} \mathrm{C}-10 \mathrm{~min}, 190^{\circ} \mathrm{C}-8 \mathrm{~min}\right.$, $210^{\circ} \mathrm{C}-5 \mathrm{~min}$ ) in order to examine the influence of the treatment severity on the extract yields and compositions. In this study the severity parameters (S) which combine temperature and duration of the SE treatment have been used (see Material and Methods section and Table 1). The condition sets used in this study were selected considering previously described works (Chadni et al. 2019). For comparison purposes, hemicelluloses were also recovered from okoume SW and HW holocellulose (after bleaching) with two commonly used methods with DMSO and with sodium hydroxide. It was reported that alkali solutions allow the extraction of hemicelluloses from bleached pulps with high yields especially for xylans. Alkaline treatment can cleave ester groups of lignocellulosic complexes in the cell wall and causes the swelling of cellulose facilitating the dissolution of hemicelluloses. On the other hand, DMSO extraction is used for the recovery of slightly modified hemicelluloses, close to their native structures but with lower yields (Evtuguin et al. 2003). Naturally acetylated hemicelluloses have been isolated using this procedure.

\subsection{Hemicelluloses yields}

Fig. 2 gives the hemicelluloses yields recovered from SW and HW after precipitation and dialysis for all the experimental conditions used in this study. As expected, from bleached pulps, higher yields were observed for alkali extractions compared to DMSO method. It is well known that unlike DMSO, alkali treatment can cleave ether and ester linkages between polysaccharides and lignin and effectively releases hemicellulose. The hemicellulose yields recovered by SE from non-bleached SW and HW are closed to those previously reported for spruce and are between $2 \%$ and $6 \% \mathrm{w} / \mathrm{w}$ (Chadni et al. 2019). For the reasons mentioned 
above, a basic impregnation of wood prior to SE has led to higher yields. However, in these latter conditions and in accordance with previous works, an increase of the SE severity led to a decrease of hemicelluloses yields due to degradation reactions such as peeling and alkaline hydrolysis (Chadni et al. 2019, 2020).

\section{Fig.2}

\subsection{Sugar compositions and molecular masses}

The composition of the hemicelluloses isolated has been established in terms of monomeric sugars by ionic chromatography after a controlled acidic hydrolysis (see experimental section). The quantification of 4-O-MeGlcU being not possible by our chromatographic method, its content was estimated by HSQC NMR (see section 3.5).

The average compositions in sugars corresponding to the 8 extraction conditions applied to SW and HW are given in Table 1. The weight average molecular masses $\mathrm{Mw}$ of the polysaccharides, assessed by water-based sized exclusion chromatography, are given in Table 1. Number average (Mn) molecular weights and polydispersities are given in Supplementary Data section S1. Whatever the experimental parameters and starting materiel (SW or HW), for all the extractions involving alkaline conditions (classical alkali extraction or SE after basic impregnation), hemicellulosic extracts were of high molecular weights $(\mathrm{Mw} \approx 60-100 \mathrm{kDa}$ ) and mainly composed of xylose with a relatively high proportion of 4-O-MeGIcU suggesting the recovery of polymeric glucuronoxylans (ratio 4-OMeGlcU / Xyl $\approx 0.35$ ). Xylose was the predominant sugar accounting for $65 \%$ to $70 \%$ of total amount of hemicellulosic sugars. It has been reported that in hardwood about $60 \%$ of noncellulosic sugars was xylose (Willfor et al. 2005).

Interestingly, it appears from Table 1 that glucuronoxylans of higher molecular masses were recovered with $\mathrm{NaOH}-\mathrm{SE}$ extraction compared to classical alkali extraction performed from bleached pulp. This observation is in accordance with previous works, the structure of the recovered hemicelluloses from SE being strongly influenced by the rapid pressure release step which open the wood structure and limit the chemical degradations (Wojtasz-Mucha et al. 2017).

The compositions of the extracts isolated with DMSO displayed a very different pattern. A lower proportion of 4-O-MeGlcU was observed (ratio 4-O-MeGlcU / Xyl $\approx 0.05-0.08$ ). Relatively high contents in mannose and glucose suggested the co-extraction of 
glucomannans (GM). A difference in composition was clearly observed between SW and HW, with a higher glucomannan content in SP. For $\mathrm{H}_{2} \mathrm{O}-\mathrm{SE}$ extraction, similar trends have been observed with higher GM co-extraction. The relatively high GM content in SW was confirmed from $\mathrm{H}_{2} \mathrm{O}$-SE extracts. GM have been reported to be the second most abundant hemicellulose in hardwood (Sjöström, 1993). In addition, Willford at al. reported a relatively high GM content in hardwood SW with varying proportions depending on the species. Mannose accounted for about 10\% of the sugars in Populus deltoides SW against only 1 to $2 \%$ in Acacia crassicarpa SP (Willfor et al. 2005).

As expected the molecular masses of hemicelluloses extracted with DMSO and water-SE were significantly lower. DMSO method solubilizes relatively low molecular mass polysaccharide fragments. Teleman et al. 2003 extracted GM from birch and aspen wood with $\mathrm{DP} \approx 16$. Chadni et al. extracted galactoglucomannans from spruce by $\mathrm{H}_{2} \mathrm{O}-\mathrm{SE}$ in the same range of severity, producing polysaccharides with comparable molecular masses $(\approx 20$ kDa) (Chadni et al. 2019, 2020). The relatively low molecular masses obtained using these conditions are justified by the well-known acid-catalyzed hydrolysis of glycosidic linkages in 300 hemicellulose chains.

\section{Table 3}

\subsection{FTIR characterization}

304 FT-IR spectra of SE hemicelluloses from HW ( $\mathrm{H}_{2} \mathrm{O}-\mathrm{SE}$ and $\left.\mathrm{NaOH}-\mathrm{SE}\right)$ are presented in Figure 3. FT-IR spectra of the other hemicellulosic fractions isolated in this study are given in Supplementary Data section S2. In $\mathrm{H}_{2} \mathrm{O}-\mathrm{SE}$ and DMSO extracts, the band at $1730 \mathrm{~cm}^{-1}$ is due to carbonyl groups stretching indicating that the hemicellulosic fractions isolated in neutral conditions are acetylated. This observation was confirmed by the presence of high-intensity band at $1244 \mathrm{~cm}^{-1}$ assigned to C-O deformation bonds of ester functions (Rowley et al., 2013). The bands at $1508 \mathrm{~cm}^{-1}\left(\delta_{\mathrm{C}-\mathrm{C}}\right)$ and $1460 \mathrm{~cm}^{-1}\left(\delta_{\mathrm{C}-\mathrm{H}}\right.$ of $\mathrm{CH}_{3}-\mathrm{O}$ groups of $\mathrm{S}$ and $\mathrm{G}$ units) suggest the presence of a high amount of residual lignin in hemicelluloses extracted in basic medium (Sun et al., 2012; Lv et al., 2013). It can also be observed that the band at $895 \mathrm{~cm}^{-1}$, 313 assigned to $\mathrm{C}^{1}-\mathrm{H}$ bonds of $\mathrm{B}-(1-4)$ - Xylp chain (Sun et al., 2016), is stronger in $\mathrm{H}_{2} \mathrm{O}-\mathrm{SE}$. This is

314 in accordance with the higher xylose contents detected by HPAE-PAD in the $\mathrm{H}_{2} \mathrm{O}-\mathrm{SE}$ extracts 315 (section 3.3). 
319 The sugar compositions of the hemicellulosic fractions were confirmed by a 2D NMR study

$320{ }^{1} \mathrm{H}_{-}{ }^{13} \mathrm{C} \mathrm{HSQC}$. The spectra were in good accordance with published data of GX and GM. For $321 \mathrm{HW}$, the main signals were assigned to sugar residues contained in GX (4-O-MeGlcUp and $322 X y \mid p)$ (Evtuguin et al. 2003, Teleman et al. 2003, Zhao et al. 2017). In SW spectra additional 323 cross-linked signals of lower intensities and assigned to Man $p$ and Glcp were detected 324 attesting the presence of GM (Campestrini et al., 2013, Martínez-Abad et al. 2018). HSQC 325 NMR spectra of hemicellulosic fractions are given in Fig. 4 and in Supplementary Materials 326 section S3. The ${ }^{1} \mathrm{H} /{ }^{13} \mathrm{C}$ cross peaks assignments are given in Table 3.

\section{$327 \quad$ Fig. 4.}

328 Table 3

329 In accordance with the FT-IR data, NMR data showed that hemicelluloses recovered with 330 DMSO and $\mathrm{H}_{2} \mathrm{O}$-SE are all acetylated. This was confirmed by ${ }^{1} \mathrm{H}$ NMR intense signals at ${ }^{1} \mathrm{H}$ at $331 \approx 2.0-2.2 \mathrm{ppm}$ assigned to $\underline{\mathrm{CH}}_{3} \mathrm{CO}$ group (Supplementary Materials section S4). It has been 332 shown that the presence of acetylated sugar residues in the polysaccharides backbone 333 results in a large number of possible monosaccharide combinations and NMR cross-peaks 334 signals, complicating the spectra considerably (Michalak et al. 2018). In alkali conditions, 335 deacetylated polysaccharides were recovered because of a further deacetylation by 336 saponification reactions.

337 For DMSO and $\mathrm{H}_{2} \mathrm{O}-\mathrm{SE}$ hemicelluloses fractions, the acetylation degree was determined by 338 HPLC after saponification (Table 1). The ${ }^{13} \mathrm{C} /{ }^{1} \mathrm{H}$ HSQC NMR correlations also helped to 339 determine distribution patterns of $O$-acetyl groups in GM and GX backbone. Evtuguin et al. 340 (2003) determined the ${ }^{13} \mathrm{C} /{ }^{1} \mathrm{H}$ correlations of acylated heteroxylans backbone by 341 homonuclear (TOCSY) and heteronuclear (HSQC) NMR experiments. Camprestrini et al. 342 (2013) characterized acetylated GM by NMR and other techniques. More recently, lignin 343 carbohydrate complexes (LCC) extracted from birch hardwood have been analyzed by 2D 344 NMR (HSQC and TOCSY). Martínez-Abad et al. (2018) described the assignment of the main $345{ }^{13} \mathrm{C} /{ }^{1} \mathrm{H}$ HSQC signals of partially acylated GX and GM in the LCC complex by HSQC NMR. In 346 this study, the ${ }^{1} \mathrm{H}$ and ${ }^{13} \mathrm{C}$ chemical shifts for the $[O-\mathrm{Ac}(1 \rightarrow 2 / 3)-\beta-D-X y \mid p]$ and $[O-A c(1 \rightarrow 2 / 3)$ -

$347 \beta$-D-Manp] are in good agreement with the values reported earlier. Based on previous 348 studies and using the data from NMR, HPLC and HPEA-PAD, a semi-quantification of $0-2,0-3$ 
and $0-2,3$ acetyl units in xylan and mannan backbones was performed (Giummarella et al.,

350 2017).

351 The results regarding the acetylation pattern are gathered in Table 4. In DMSO, very

352 different acetylation patterns were observed for SW and HW. Interestingly, SW

353 hemicelluloses are more highly acetylated than $\mathrm{HW}(4.1 \%$ and $1.0 \%$ respectively). $\mathrm{A}$

354 comparable trend was observed for the water-SE extracts with significantly higher acetyl

355 contents (6.2\% and $8.4 \%$ for HW and SW respectively). It has been previously reported that

356 hemicelluloses isolated from hardwood SW exhibited higher degree of branching and lower

357 xylose content (Xiao et al., 2020) but, to our knowledge, a comparison of the acetyl content

358 of SW and HW hemicelluloses has never been investigated. The higher acetylation degree of

359 SW hemicelluloses reported in the present study could be one of the factors contributing to

360 the higher porosity and water permeability of SW (Ramachandriya et al., 2014). In okoume

361 SP, comparable results were obtained for DMSO and $\mathrm{H}_{2} \mathrm{O}-\mathrm{SE}$ in terms of acetylation pattern.

362 Both GX and GM are $\mathrm{O} 2$ and $\mathrm{O} 3$ acetylated, the degree of acetylation being slightly higher

363 for $\mathrm{GM}$ compared to $\mathrm{GX}\left(\mathrm{DS}_{\mathrm{Ac}}\right.$ Man $p \approx 0.25$ and $\mathrm{DS}_{\mathrm{Ac}} \mathrm{Xy} \mid p=0.20$ respectively). For $\mathrm{HW}$, a

364 significantly higher acetylation degree was also found for $\mathrm{H}_{2} \mathrm{O}-\mathrm{SE}$ compared to DMSO, GX

365 being acetylated at position $O 2$ and/or $O 3\left(D_{A c} X y l p=0.26\right)$. These results are close to those

366 previously obtained from spruce and the recovery of galactoglucomannans (GGM) by $\mathrm{H}_{2} \mathrm{O}-\mathrm{SE}$

367 with $\mathrm{DS}_{\mathrm{Ac}} \approx 0.27-0.35$, very similar to the values reported for native Ac-GGM Chadni et al.

3682019,2020 . Thus, these results confirm that SE allowed to extract highly acetylated and

369 slightly modified polymeric hemicelluloses. The acetylation degree of hemicelluloses

370 strongly affecting the physico-chemical properties of the resulting materials (e.g. barrier

371 properties of films, Kishani et al., 2018), these experimental results could help to develop an

372 extraction route from okoume waste wood for the design of films and materials with

373 controlled properties.

\section{Table 4}

\section{Conclusion}

377 Steam explosion (SE) pretreatment was assessed for the extraction of high molecular weight

378 hemicelluloses directly from okoume SW and HW and compared to traditional extraction

379 methods with DMSO and alkali solution performed from bleached wood. The SE parameters

380 which include a short steaming duration and a mechanical defibration limit the 
381 polysaccharide hydrolytic breakdown and enhance the efficiency of the subsequent

382 extraction. The recovery of high molecular weight GX was performed using a SE treatment

383 after basic impregnation. On the other hand, after a water pre-soaking, SE allowed the

384 recovery of a mixture of highly $\mathrm{O} 2$ and/or $\mathrm{O} 3$ acetylated $\mathrm{GX}$ and GM. It clearly appeared that

$385 \mathrm{H}_{2} \mathrm{O}$-SE preserved the acetyl moieties in a greater extent compared to the mild DMSO

386 extraction. The results obtained in our study showed that (1) SE can be employed for the

387 extraction of complex polysaccharides from wood for characterization purposes, (2) okoume

388 wood hemicelluloses are primarily composed of highly acetylated GX with a relatively high

389 amount of acetylated GM in the SW. The impact of this work could involve better recovery

390 of waste from the okoume industry in Gabon with a view to the production of hemicellulose-

391 based materials.

393 Author Contributions: “Conceptualization, N.B., RST; methodology, EMM, IZD.;

394 investigation, EMM; writing-original draft preparation, N.B.; writing-review and editing,

395 N.B., EMM, IZD, RST; supervision, N.B.; funding acquisition, RFT. All authors have read and

396 agreed to the published version of the manuscript."

397 Acknowledgments: The EA 4370 LERMAB is also supported by the French National Research

398 Agency through the Laboratory of Excellence ARBRE (ANR-12-LABXARBRE-01). The National

399 Agency of Fellowships of Gabon (ANBG) and Campus France are thanked for the financial

400 support granted to the PhD student Errol MOUGNALA MOUKAGNI. The authors thank the

401 NMR plateform, Institut Jean Barriol, CRM2, Lorraine University - CNRS. 


\section{References}

Campestrini, L.H., Silveira, J.L.M., Duart, M.E.R., Koop H.S., Noseda, M.D., 2013. NMR and rheological study of Aloe barbadensis partially acetylated glucomannan, Carbohydrate Polymers 94(1), 511-519.

Chadni, M., Grimi, N., Bals, O., Ziegler-Devin, I., Brosse, N., 2019. Steam explosion process for the selective extraction of hemicelluloses polymers from spruce sawdust, Ind. Crops Prod. 141, 111757.

Chadni, M., Grimi, N., Bals, O., Ziegler-Devin, I., Desobry, S., Brosse, N. 2020. Elaboration of hemicellulose-based films: Impact of the extraction process from spruce wood on the film properties. Carbohydrate Research. 497, 108111.

Engozogho, A.S.P., Bikoro Bi Athomo, A., Vidal, M.; Denaud, L., Safou Tchiama R., Charrier B., 2019. Extraction and Characterization of Aucoumea klaineana Pierre (Okoume) Extractives. Journal of Renewable Materials 7(6), 517-522.

Espirito Santo, M.C., Fockink, D.H., Pellegrini, V.O.A., Guimaraes, F.E.G., de Azevedo, E.R., Ramos, L.P., Polikarpov, I., 2020. Physical techniques shed light on the differences in sugarcane bagasse structure subjected to steam explosion pretreatments at equivalent combined severity factors Industrial Crops and Products 158, 113003.

Evtuguin, D.V., Tomas, J.L., Silva, A.M.S., Neto, C.P., 2003. Characterization of an acetylated heteroxylan from Eucalyptus globulus Labill. Carbohydrate Research 338, 597-604

Giummarella, N., Lawoko, M. 2017. Structural Insights on Recalcitrance during Hydrothermal Hemicellulose Extraction from Wood. ACS Sustainable Chem. Eng. 5, 5156-5165

Inseemeesak, B., Areeprasert, C. 2020. Fiber extraction and energy recovery from Cocos nucifera Linn mesocarp residues employing steam explosion and anaerobic digestion. Industrial Crops and Products 147, 112180.

Ishii, T., Shimizu, K. Chemistry of cell wall polysaccharides (2001), In Hon, D.N.-S.; Shiraishi, N. Wood and cellulose chemistry, second edition (p175-212), Marcel Dekker Inc., New York (USA).

Kishani, S., Vilaplana, F., Xu, W., Xu, C., Wågberg, L. 2018. Solubility of Softwood Hemicelluloses Biomacromolecules 19, $1245-1255$.

Krawczyk, H., Persson, T., Andersson, A., Jonsson, A.-S., 2008. Isolation of hemicelluloses from barley husks. Food and bioproducts processing 86, 31-36.

Marques, G., Gutierrez, A., del Rio, J., Evtuguin, D.V., 2010. Acetylated heteroxylan from Agave sisalana and its behavior in alkaline pulping and TCF/ECF bleaching, Carbohydrate Polymers 81, 517-523.

Marques, F.P., Silva, L.M.A., Lomonaco, D., Rosa, M.D.F., Leitao, R.C., 2020. Steam explosion pretreatment to obtain eco-friendly building blocks from oil palm mesocarp fiber, Industrial Crops and Products Volume 143, 111907.

Martínez-Abad, A., Giummarella, N., Lawoko M., Vilaplana F., 2018. Differences in extractability under subcritical water reveal interconnected hemicellulose and lignin recalcitrance in birch hardwoods. Green Chem. 20, 2534-2546.

Michalak, L., Knutsen, S.H., Aarum, I., Westereng, B., 2018. Effects of pH on steam explosion extraction of acetylated galactoglucomannan from Norway spruce. Biotechnol. Biofuels 11, 311. 
Ngwa Obame, S., Ziegler-Devin, I., Safou Tchima, R., Brosse, N., 2019. Homolytic and heterolytic cleavage of beta-ether linkages in hardwood lignin by Steam Explosion, Journal of Agricultural and Food Chemistry 67(21), 5989-5996.

Overend, R. P., Chornet, E., 1987. Fractionation of lignocellulosics by steam-aqueous pretreatments. Philos. Trans. R. Soc., A 321, 523-536.

Ramachandriya, K.D., Wilkins, M., Pardo-Planas, O., Atiyeh, H.K., Dunford, N.T., Hiziroglu, S., 2014. Simultaneous saccharification and fermentation of Eastern redcedar heartwood and sapwood using a novel size reduction technique. Bioresour. Technol. 161, 1-9.

Safou-Tchiama, R., de Jeso, B., Akagah, A.G., Sebe, G., Petraud, M. A., 2007. Survey of the interfacial bonding of some tropical hardwoods towards succinic anhydride and 2-octen-1-yl succinic anhydride molecules: Impact of lignin and carbohydrate polymers structure on the chemical reactivity. Industrial Crops and Products 26, 173-184.

Safou-Tchiama, R., Ngwa Obame, S., Andzi Barhé, T., Bikanga Bill, R., Brosse, N., 2016. An investigation of Aucoumea klaineana Pierre heartwood and sapwood wastes potential for cellulosic ethanol production: Ethanol Organosolv Lignin and fermentable sugars recovery. African Journal of Biotechnology 15(46) 2587-2595.

Sjöström, E. (1993) Wood Chemistry. Fundamentals and Applications, 2nd edition, Academic Press, San Diego, CA, USA, 293.

Teleman, A., Tenkanen, M., Jacobs, A., Dahlmana, O., 2002. Characterization of $O$-acetyl-(4-O-methylglucurono)xylan isolated from birch and beech. Carbohydrate Research 337, 373-377.

Teleman, A., Nordstrom, M., Tenkanen, M., Jacobs, A., Dahlmana, O., 2003. Isolation and characterization of $O$-acetylated glucomannans from aspen and birch wood, Carbohydrate Research 338, 525-534.

Voepel, J., Sjoberg, J., Reif, M., Albertsson, A.C., Hultin, U.-K., Gasslander, U., 2009. Drug Diffusion in Neutral and lonic Hydrogels Assembled from Acetylated Galacto-glucomannan. Journal of Applied Polymer Science 112, 2401-2412.

Willfor, S., Sjöholm, R., Laine, C., Roslund, M., Hemming, J., Holmbom, B., 2003. Characterisation of water-soluble galactoglucomannans from Norway spruce wood and thermomechanical pulp. Carbohydr. Polym. 52(2), 175-187.

Willfor, S., Sundberg, A., Pranovich, A., Holmbom, B., 2005. Polysaccharides in some industrially important hardwood species. Wood Sci. Technol. 39, 601-617.

Wojtasz-Mucha, J., Hasani, M., Theliander, H., 2017. Hydrothermal pretreatment of wood by mild steam explosion and hot water extraction. Bioresour Technol. 241,120-126.

Xiao, M.-Z., Chen, W.-J., Cao, X.F., Chen, Y.-Y., Zhao, B.-C., Jiang, Z.-H., Yuan, T.-Q., Sun, R.-C., 2020. Unmasking the heterogeneity of carbohydrates in heartwood, sapwood, and bark of Eucalyptus. Carbohydrate Polymers 238, 116212.

Yuan, X., Wang, J., Yao, H., 2006. Production of feruloyl oligosaccharides from wheat bran insoluble dietary fibre by xylanases from Bacillus subtilis. Food Chemistry. 95, 489-492.

Zhao, Y., Sun, H., Yang, B., Weng, Y., 2020. Hemicellulose-based film potential green films for food packaging. Polymers 12(8), 1775.

Zhao, X., Tong, T., Li, H., Lu, H., Ren, J., Zhang, A., Deng, X., Chen, X., Wu, A.-M., 2017. Characterization of hemicelluloses from Neolamarckia cadamba (Rubiaceae) during xylogenesis. Carbohydrate Polymers 156, 333-339. 
Table 1. Composition of sugars, acetic acid (\% of dry mass of hemicelluloses molar mass of hemicelluloses) and average (Mw in KDa) of hemicelluloses

\begin{tabular}{|c|c|c|c|c|c|c|c|c|c|c|c|c|c|c|}
\hline Treatment & & $\mathrm{Impr}^{\mathrm{a}}$ & $S^{o b}$ & $x y l^{c}$ & GIUOMe $^{d}$ & $\operatorname{Man}^{c}$ & $\mathrm{Glc}^{\mathrm{c}}$ & $\mathrm{Ara}^{\mathrm{C}}$ & $\mathrm{Gal}^{\mathrm{c}}$ & $\mathrm{Rha}^{\mathrm{c}}$ & $\mathrm{GalA}^{\mathrm{c}}$ & $\mathrm{GlcA}^{\mathrm{c}}$ & $A c^{e}$ & $M w^{f}$ \\
\hline \multirow{2}{*}{$\mathrm{NaOH}^{\mathrm{e}}$} & SW & & & $43.1 \pm 1.0$ & & n.a & $1.7 \pm 0.1$ & $2.4 \pm 0.1$ & $1.7 \pm 0.1$ & $1.1 \pm 0.0$ & $2.9 \pm 0.1$ & $0.4 \pm 0.0$ & - & 64 \\
\hline & $\mathrm{HW}$ & & & $34.1 \pm 2.6$ & 11.1 & n.a & $0.1 \pm 0.1$ & $0.3 \pm 0.0$ & $1.4 \pm 0.1$ & $0.9 \pm 0.0$ & $1.6 \pm 0.2$ & $0.3 \pm 0.0$ & - & 56 \\
\hline \multirow{2}{*}{$\mathrm{DMSO}^{\mathrm{g}}$} & sW & & & $16.0 \pm 0.8$ & 1.3 & $17.0 \pm 0.6$ & $27.4 \pm 1.6$ & $0.7 \pm 0.0$ & $1.5 \pm 0.0$ & $0.5 \pm 0.0$ & $1.1 \pm 0.1$ & $0.4 \pm 0.0$ & 4.1 & 29 \\
\hline & $\mathrm{HW}$ & & & $44.3 \pm 0.3$ & 2.2 & $11.5 \pm 0.4$ & $11.0 \pm 0.2$ & $0.2 \pm 0.0$ & $0.9 \pm 0.0$ & $0.7 \pm 0.1$ & $0.9 \pm 0.0$ & $0.3 \pm 0.0$ & 1.0 & 24 \\
\hline \multirow{12}{*}{$\begin{array}{c}\text { Steam } \\
\text { explosion }\end{array}$} & \multirow{3}{*}{ sW } & $\mathrm{H}_{2} \mathrm{O}$ & 3.1 & $47.7 \pm 1.7$ & 2.4 & $11.3 \pm 0.8$ & $9.3 \pm 0.3$ & $0.5 \pm 0.0$ & $5.4 \pm 0.2$ & $4.6 \pm 0.1$ & $5.4 \pm 0.2$ & $9.3 \pm 0.2$ & 8.4 & 9 \\
\hline & & $\mathrm{H}_{2} \mathrm{O}$ & 3.6 & $44.5 \pm 1.5$ & & $5.6 \pm 0.2$ & $25.7 \pm 1.0$ & $0.4 \pm 0.0$ & $4.4 \pm 0.2$ & $0.9 \pm 0.1$ & $0.9 \pm 0.1$ & $0.2 \pm 0.0$ & 8.1 & 26 \\
\hline & & $\mathrm{H}_{2} \mathrm{O}$ & 3.9 & $29.4 \pm 0.1$ & & $4.9 \pm 0.0$ & $34.3 \pm 0.2$ & $0.1 \pm 0.0$ & $3.4 \pm 0.0$ & $0.4 \pm 0.0$ & $0.5 \pm 0.0$ & $0.1 \pm 0.0$ & 8.0 & 21 \\
\hline & \multirow{3}{*}{ HW } & $\mathrm{H}_{2} \mathrm{O}$ & 3.1 & $54.9 \pm 11.7$ & 1.1 & $2.6 \pm 2.6$ & $1.2 \pm 0.8$ & $2.2 \pm 2.0$ & $10.1 \pm 5.5$ & $1.9 \pm 1.7$ & $6.8 \pm 0.2$ & $0.8 \pm 0.0$ & 6.2 & 10 \\
\hline & & $\mathrm{H}_{2} \mathrm{O}$ & 3.6 & $44.7 \pm 2.1$ & & $2.3 \pm 0.2$ & $1.3 \pm 0.1$ & $0.1 \pm 0.0$ & $3.2 \pm 0.2$ & $0.1 \pm 0.1$ & $1.5 \pm 0.2$ & $0.2 \pm 0.0$ & 7.7 & 11 \\
\hline & & $\mathrm{H}_{2} \mathrm{O}$ & 3.9 & $64.4 \pm 1.9$ & & $4.2 \pm 0.2$ & $3.1 \pm 0.1$ & $0.1 \pm 0.0$ & $5.6 \pm 0.2$ & $1.5 \pm 0.0$ & $2.0 \pm 0.1$ & $0.3 \pm 0.0$ & 6.6 & 6 \\
\hline & \multirow{3}{*}{ SW } & $\mathrm{NaOH}$ & 3.1 & $30.7 \pm 1.1$ & 10.1 & n.a & $0.8 \pm 0.0$ & $1.4 \pm 0.1$ & $1.7 \pm 0.1$ & $1.4 \pm 0.1$ & $0.6 \pm 0.0$ & $0.4 \pm 0.1$ & - & 97 \\
\hline & & $\mathrm{NaOH}$ & 3.6 & $24.1 \pm 1.3$ & & $0.2 \pm 0.1$ & $11.8 \pm 0.7$ & $1.7 \pm 0.1$ & $3.0 \pm 0.2$ & $1.7 \pm 0.1$ & $0.4 \pm 0.0$ & $0.2 \pm 0.0$ & - & 104 \\
\hline & & $\mathrm{NaOH}$ & 3.9 & $30.4 \pm 0.1$ & & $0.2 \pm 0.0$ & $5.6 \pm 0.0$ & $1.6 \pm 0.0$ & $1.7 \pm 0.0$ & $0.3 \pm 0.0$ & $0.2 \pm 0.0$ & $0.2 \pm 0.0$ & - & 86 \\
\hline & \multirow{3}{*}{$\mathrm{HW}$} & $\mathrm{NaOH}$ & 3.1 & $44.1 \pm 1.0$ & 15.9 & n.a & $0.3 \pm 0.0$ & $0.4 \pm 0.0$ & $1.0 \pm 0.0$ & $0.9 \pm 0.0$ & $0.8 \pm 0.0$ & $0.3 \pm 0.0$ & - & 64 \\
\hline & & $\mathrm{NaOH}$ & 3.6 & $29.0 \pm 5.4$ & & $0,1 \pm 0.1$ & $0.2 \pm 0.0$ & $0.3 \pm 0.1$ & $1.4 \pm 0.3$ & $0.5 \pm 0.1$ & $0.5 \pm 0.1$ & $0.1 \pm 0.0$ & - & 69 \\
\hline & & $\mathrm{NaOH}$ & 3.9 & $40.1 \pm 6.3$ & & $0.1 \pm 0.0$ & $0.2 \pm 0.0$ & $0.4 \pm 0.1$ & $1.2 \pm 0.2$ & $0.4 \pm 0.1$ & $0.3 \pm 0.0$ & $0.1 \pm 0.0$ & - & 70 \\
\hline
\end{tabular}

${ }^{\mathrm{a}}$ Impregnation conditions prior to SE; ${ }^{\mathrm{b}}$ Severity factor of SE; ${ }^{\mathrm{c} X y l o s e}$, mannose, glucose, arabinose, galactose, Rhamnose, galacturonic and glucuronic acid $\%$, determined after hydrolysis by HPEAC-PAD; ${ }^{\mathrm{d}}$ estimation by HSQC-NMR; ${ }^{\mathrm{e}}$ acetic acid quantified by HPLC after saponification; ${ }^{\mathrm{f}}$ determined by SEC; ${ }^{\mathrm{g}}$ extraction from holocellulose; ${ }^{\mathrm{h}}$ extraction from wood by SE 
Table 2. Chemical composition (\% of dry wood) of raw wood.

\begin{tabular}{ccc} 
& SW $^{\mathbf{a}}$ & $\mathbf{H W}^{\mathbf{b}}$ \\
\hline Extracts $^{\mathrm{a}}$ & $2.36 \pm 0.31$ & $2.00 \pm 0.41$ \\
Klason lignin & $29.68 \pm 1.58$ & $28.02 \pm 0.37$ \\
Fuc & $0.02 \pm 0.00$ & $0.00 \pm 0.00$ \\
Rha & $0,27 \pm 0.04$ & $0.24 \pm 0.05$ \\
Ara & $0.52 \pm 0.04$ & $0.11 \pm 0.01$ \\
Gal & $0.68 \pm 0.01$ & $0.56 \pm 0.02$ \\
Glc & $50.73 \pm 0.15$ & $54.19 \pm 1.66$ \\
Xyl & $11.34 \pm 0.04$ & $10.16 \pm 2.41$ \\
Man & $2.23 \pm 0.03$ & $2.09 \pm 0.15$ \\
GalA & $0.49 \pm 0.28$ & $0.64 \pm 0.04$ \\
GlcA & $0.13 \pm 0.04$ & $0.08 \pm 0.07$
\end{tabular}

Means of three independent analyses. ${ }^{\mathrm{a}} \mathrm{Sapwood} ;{ }^{\mathrm{b}} \mathrm{Heartwood} ;{ }^{\mathrm{c}}$ Toluene-ethanol-methanol extracts (see Material $\&$ methods section) 
Table 3. Chemical shifts (ppm) of ${ }^{1} \mathrm{H}$ NMR spectra

\begin{tabular}{|c|c|c|c|c|c|c|c|c|c|}
\hline & \multirow[t]{2}{*}{ Impregnation } & \multirow[t]{2}{*}{ Structural Units } & \multicolumn{7}{|c|}{ Attributions } \\
\hline & & & 1 & 2 & 3 & 4 & $5 e q$ & $5 a x$ & 6 \\
\hline \multirow[t]{16}{*}{ SW } & $\mathrm{NaOH}$ & Xyl (isol.) & 4.31 & 3.28 & 3.55 & & & 3.40 & \\
\hline & & Xyl (Xyl-Ac) & 4.42 & 3.23 & & & & 3.35 & \\
\hline & & $\alpha$ Ara-3Xyl & & & & 4.27 & & & \\
\hline & & MeGlcA & & 3.51 & 3.73 & 3.16 & 4.31 & & \\
\hline & $\mathrm{H}_{2} \mathrm{O}$ & Xyl (isol.) & 4.31 & 3.8 & 3.57 & 3.79 & & 3.40 & \\
\hline & & Xyl (Xyl-Ac) & 4.41 & 3.23 & 3.55 & 3.76 & & 3.39 & \\
\hline & & Xyl-3Ac & 4.58 & 3.47 & 4.98 & 4.93 & & & \\
\hline & & Xyl-2Ac & & 4.57 & 3.62 & 3.86 & & & \\
\hline & & Xyl-2.3Ac & & & 5.12 & 4.07 & & & \\
\hline & & Xyl-2Ac-2MeGlcA & & & 5.02 & & & & \\
\hline & & $\alpha$ Ara-3Xyl & 5.36 & & & 4.26 & & & \\
\hline & & Xyl-2.3Ara & 5.22 & & & & & & \\
\hline & & Man (Man-Ac) & & 4.03 & 3.65 & & & & \\
\hline & & Man-2Ac & 4.88 & 5.44 & & & & & \\
\hline & & Man-3Ac & & 4.17 & & & & & \\
\hline & & MeGlcA & 5.29 & 3.57 & 3.72 & & & 4.31 & \\
\hline \multirow[t]{17}{*}{ HW } & $\mathrm{NaOH}$ & Xyl (isol.) & 4.41 & 3.28 & & & & 3.37 & \\
\hline & & $x y(X y l-A c)$ & 4.42 & 3.23 & 3.53 & & & 3.36 & \\
\hline & & $\alpha$ Ara-3Xyl & & & & 4.26 & & & \\
\hline & & Xyl-2.3Ara & 5.23 & & & & & & \\
\hline & & MeGlcA & & 3.57 & 3.73 & 3.16 & & 4.31 & \\
\hline & $\mathrm{H}_{2} \mathrm{O}$ & Xyl (isol.) & 4.41 & 3.28 & 3.55 & 3.79 & & 3.40 & \\
\hline & & Xyl(Xyl-Ac) & 4.42 & 3.23 & 3.54 & 3.76 & & 3 & \\
\hline & & Xyl-3Ac & 4.56 & 3.49 & 5.0 & 4.93 & & & \\
\hline & & Xyl-2Ac & & 4.57 & 3.62 & 3.88 & & & \\
\hline & & Xyl-2.3Ac & & & 5.12 & 4.04 & & & \\
\hline & & Xyl-2Ac-2MeGlcA & & & 5.01 & & & & \\
\hline & & $\alpha$ Ara-3Xyl & & & & 4.27 & & & \\
\hline & & Xyl-2.3Ara & 5.23 & & & & & & \\
\hline & & Man (Man-Ac) & & 4.03 & 3.65 & & & & \\
\hline & & Man-2Ac & 4.90 & & & & & & \\
\hline & & Man-3Ac & & 4.17 & & & & & \\
\hline & & MeGlcA & & 3.57 & 3.72 & 3.16 & 4.31 & & \\
\hline
\end{tabular}

Xyl (isol.): non-acetylated Xylp unit in the skeleton isolated from another acetylated unit; Xyl (Xyl-Ac): nonacetylated Xylp unit linked with an acetylated neighbor; Xyl-3Ac: 3-O-acetylated Xylp unit; Xyl-2Ac: 2-Oacetylated Xylp unit; Xyl-2,3Ac: 2,3-di-O-acetylated Xylp unit; Xyl-3Ac-2GlcA: Xylp unit carrying a 2-O- and 3-Oacetylated MeGlcA; a-Ara-3Xyl: Ara terminal $O-3$ bonded to a monosubstituted Xylp unit; MeGlcA: $O-2$ bonded MeGlcA terminal residue; a-Ara-3Xyl: Ara terminal $O-3$ bonded to a monosubstituted Xylp unit; MeGlcA: O-2 bonded MeGlcA terminal residue.to monosubstituted Xylp and also 3-O-acetylated. 
Table 4. Acetylation degree of hemicelluloses

\begin{tabular}{|c|c|c|c|c|c|c|}
\hline & & $A c \%^{a}$ & $\mathrm{DS}_{\mathrm{AC}} \operatorname{Man}^{\mathrm{b}}$ & 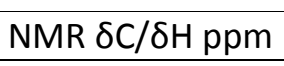 & $\mathrm{DS}_{\mathrm{Ac}} \mathrm{Xyl} p^{\mathrm{c}}$ & NMR $\delta C / \delta \mathrm{H} p p m$ \\
\hline \multirow{4}{*}{ DMSO } & SW & 4.1 & \multirow{2}{*}{0,24} & $0-2$ 71.85/5.30 & \multirow{2}{*}{0,18} & 0-2 73.85/4.52 \\
\hline & & & & $0-3-$ & & 0-3 75.45/4.82 \\
\hline & \multirow[t]{2}{*}{$\mathrm{HW}$} & \multirow[t]{2}{*}{1.0} & \multirow{2}{*}{0,02} & $0-2-$ & \multirow{2}{*}{0,04} & $0-2$ 70.25/4.50 \\
\hline & & & & 0-3 73.36/4.96 & & 0-3 75.45/4.82 \\
\hline \multirow{6}{*}{$\mathrm{H}_{2} \mathrm{O}-\mathrm{SE}$} & \multirow[t]{3}{*}{ SW } & \multirow[t]{3}{*}{8.4} & \multirow{3}{*}{0,25} & O-2 73.66/5.28 & \multirow{3}{*}{0,20} & $0-271.02 / 4.50$ \\
\hline & & & & 0-3 75.47/5.19 & & $0-2,372.00 / 4.84$ \\
\hline & & & & & & O-3 77.13/4.64 \\
\hline & \multirow[t]{3}{*}{ HW } & \multirow[t]{3}{*}{6.2} & \multirow{3}{*}{0,08} & O-2 73.13/5.25 & \multirow{3}{*}{0,26} & O-2 72.55/4.50 \\
\hline & & & & $0-3-$ & & $0-2,372.00 / 4.84$ \\
\hline & & & & & & O-3 77.13/4.64 \\
\hline
\end{tabular}

${ }^{a}$ Ac: Acetic acid (\% of dry mass of hemicelluloses after saponification); ${ }^{b} D S_{A C}$ Manp: Degree of substitution of mannose residue with acetyl groups; ${ }^{C} D S_{A C x y l p}$ : Degree of substitution of xylose residue with acetyl groups. 
$\mathrm{NaOH} \mathrm{SW}$

$\mathrm{NaOH} \mathrm{HW}$

Okoume

$\uparrow \mathrm{NaOH}$

Steam Explosion

holocellulose

DMSO SW

DMSO Bleachin
extraction

$\log R^{\circ}=3.06,3.55$ or 3.94

$\mathrm{H}_{2} \mathrm{O}$ or $\mathrm{NaOH}$ impregnation

Okou

sawdust

NaQH-SE SW

NaOH-SE HW

DMSO HW

$\mathrm{H}_{2} \mathrm{O}-\mathrm{SE} S \mathrm{~W}$

$\mathrm{H}_{2} \mathrm{O}-\mathrm{SE} \mathrm{HW}$ 
Figure 2. Polymeric hemicelluloses yields (\% of dry mass of the initial wood)

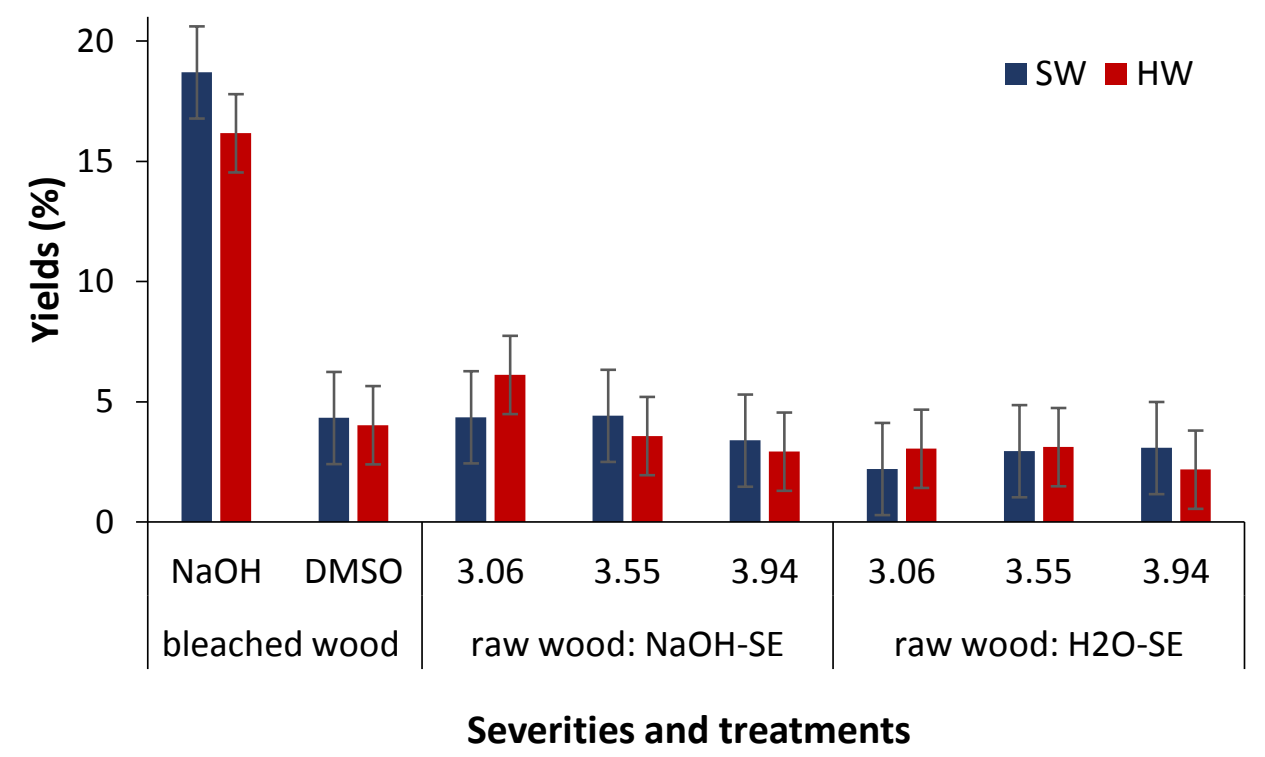


Figure 3. FT-IR Spectra of SE-extracted hemicelluloses $\left(\mathrm{H}_{2} \mathrm{O}-\mathrm{SE} \mathrm{HW}\right.$ and $\mathrm{NaOH}-\mathrm{SE}$ $\mathrm{HW}, \mathrm{S}=3.1$ )

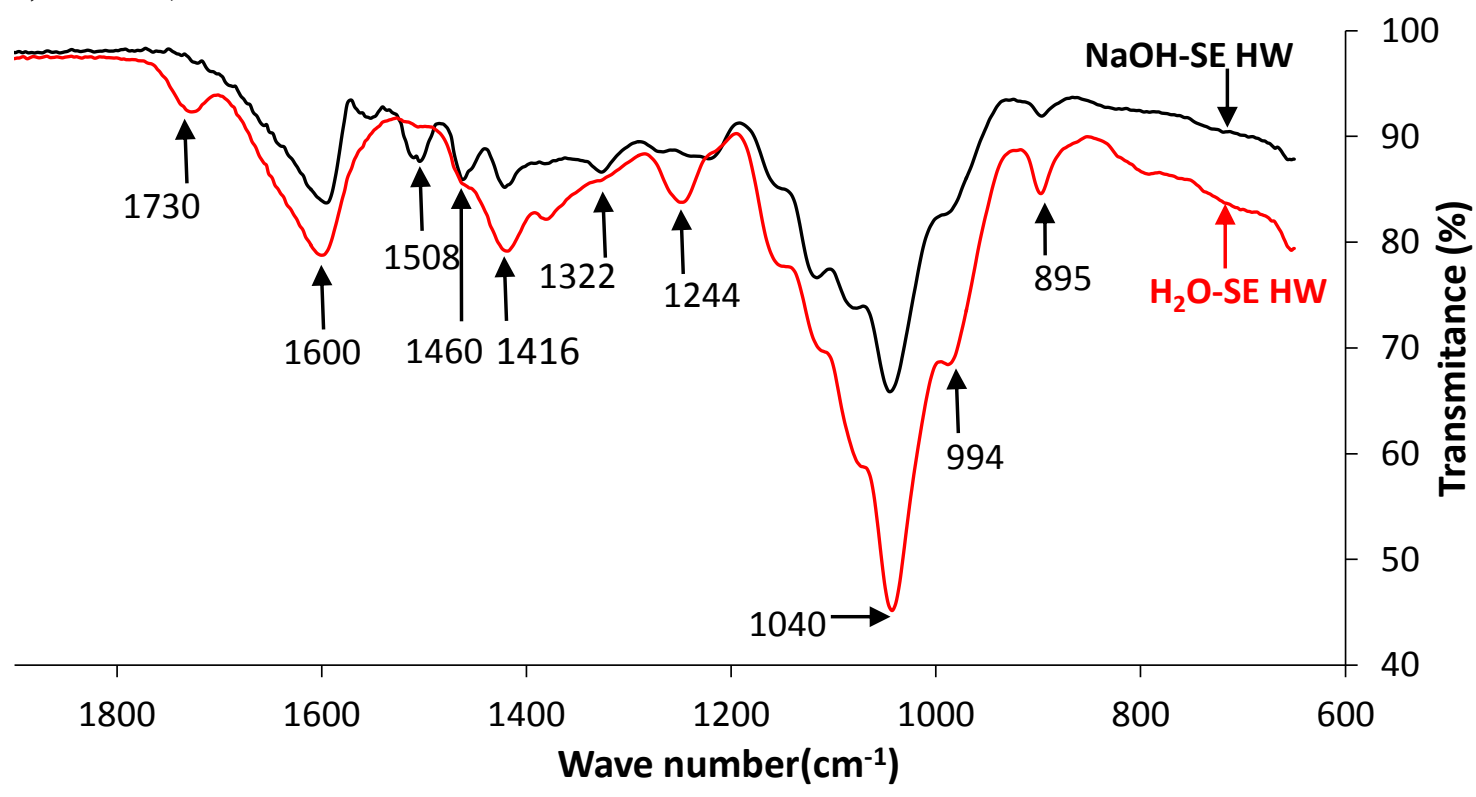


Fig. 4 2D HSQC NMR Spectral analysis of SE extracted hemicelluloses. ${ }^{\text {a }}$

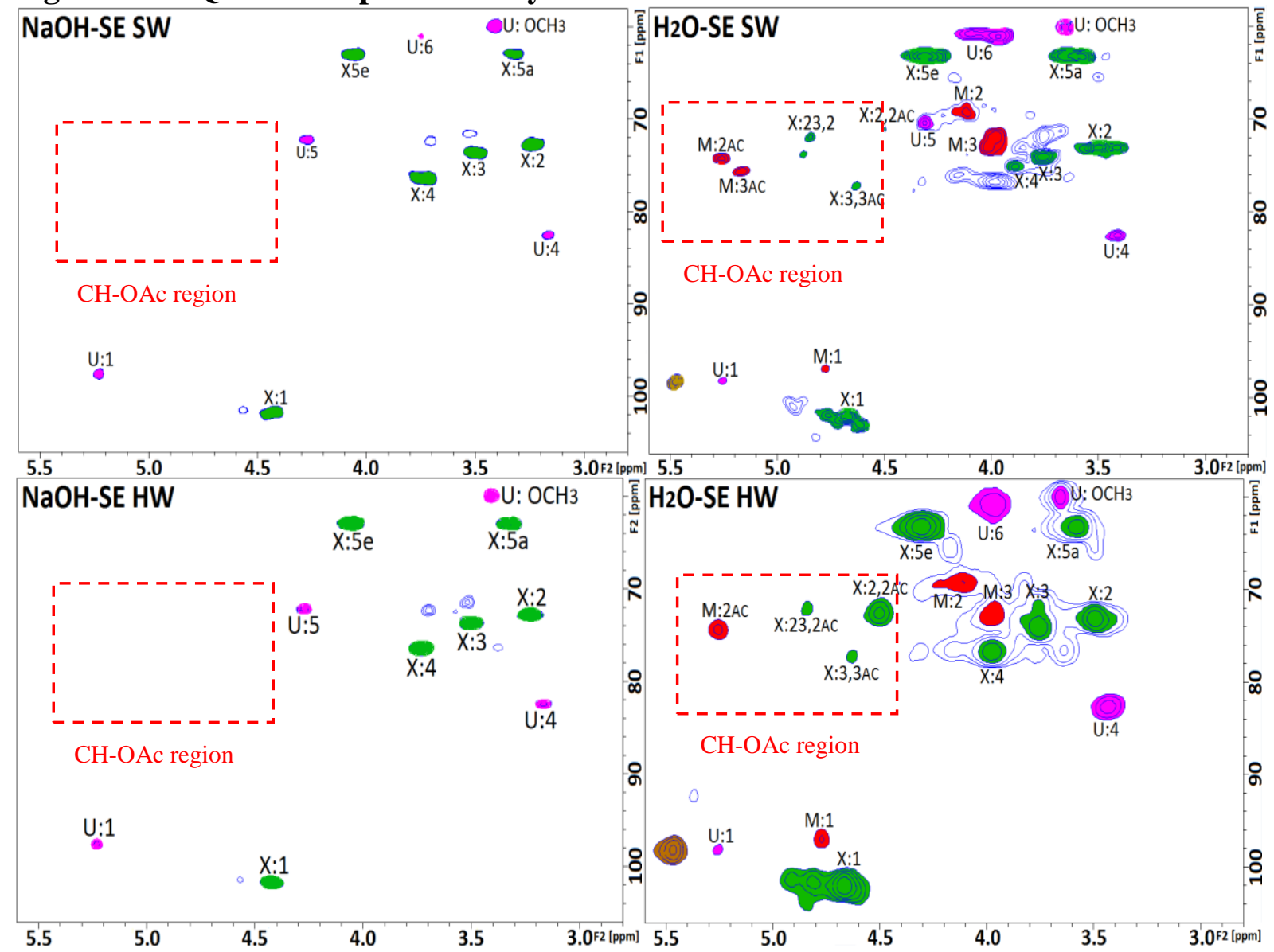

${ }^{a} \mathrm{X}:(1 \rightarrow 4) \boldsymbol{\beta}$-D-Xylopyranosyl ; U: 4-O-methyl- $\boldsymbol{\alpha}$-D-glucuronic acid ; M: $(1 \rightarrow 4) \boldsymbol{\beta}$-D-

Mannosyl ;

G: $(1 \rightarrow 4) \boldsymbol{\beta}$-D- Glucosyl ; Ac: acetyl. 